\title{
Substituição do milho pelo sorgo sobre o desempenho zootécnico e na digestibilidade em coelhos
}

[Replacement of corn by sorghum on zootechnical performance and digestibility in Rabbits]

J.M. Parreira Filho ${ }^{1,3}$, E.A. Fernandes ${ }^{2}$, R.F.M. Guimarães ${ }^{3}$, C.B. Oliveira $^{3}$, B.B.B. Freitas ${ }^{3}$, L.F. Santana ${ }^{3}$, C. Fudimoto ${ }^{4}$, I.F.B. Parreira ${ }^{4}$, P.M.L. Oliveira ${ }^{4}$

${ }^{1,3}$ Aluno de pós-graduação - Universidade Federal de Uberlândia - Uberlândia, MG

${ }^{2}$ Universidade Federal de Uberlândia - Uberlândia, MG

${ }^{3}$ Instituto Federal de Educação, Ciência e Tecnologia do Triângulo Mineiro - Uberaba, MG

${ }^{4}$ Aluno de graduação - Instituto Federal de Educação, Ciência e Tecnologia do Triângulo Mineiro - Uberaba, MG

\section{RESUMO}

O milho é a principal fonte de energia nas dietas animais. Em algumas regiões brasileiras, sua disponibilidade, principalmente na entressafra, é insuficiente para atender à demanda, fazendo com que seu preço se eleve. Neste estudo, objetivou-se avaliar a substituição do milho pelo sorgo sobre o desempenho zootécnico e a digestibilidade em coelhos. Foram utilizados 60 animais machos da raça Nova Zelândia Branco, divididos em três tratamentos: ração base milho (TM); ração base sorgo (TS) e ração base $50 \%$ de milho $+50 \%$ de sorgo (TMS). No ensaio de desempenho, avaliou-se ganho de peso (GP), consumo de ração (CR), conversão alimentar (CA), coeficientes de digestibilidade da matéria seca (CDMS), proteína bruta (CDPB), fibra em detergente neutro (CDFDN) e fibra em detergente ácido (CDFDA). Observou-se que o CRM, a CA e o GPM não foram afetados pela substituição do milho pelo sorgo, nos níveis de 50\% e $100 \%$. Os resultados de digestibilidade demonstraram maiores CDPB e CDFDN na ração base milho, não havendo diferenças entre os demais parâmetros estudados. $\mathrm{O}$ sorgo com baixo teor de tanino pode ser usado nas rações de crescimento de coelhos em níveis de substituição de $50 \%$ ou $100 \%$ da participação do milho, sem prejuízos para o desempenho zootécnico e a digestibilidade.

Palavras-chave: Zea mays, Sorghum bicolor, coelhos, nutrição

\begin{abstract}
Corn is the main source of energy in animal diets. In some Brazilian regions, its availability, especially in the off-season, may be insufficient to meet demand, which causes prices to increase. In this context, the aim of this study was to evaluate the substitution of maize by sorghum on the performance and digestibility of rabbits. Sixty New Zealand White bucks were used, divided in three treatments, maize base ration (TM); based on grain sorghum ration (TS) and base ration 50\% corn $+50 \%$ sorghum grain (TMS). In the performance test, weight gain (GP), feed intake (CR) and feed conversion ratio (CA) were evaluated. In the digestibility assay, 21 animals were used. The total dry matter (CDMS), crude protein (CDPB), gross energy $(E B)$, neutral detergent fiber $(C D F D N)$ and acid detergent fiber (CDFDA) coefficients were evaluated. There was no significant difference for any of the performance parameters studied $(P>0.05)$. The digestibility results showed higher $C D P B$ and $C D F D N$ in the corn diet $(P<0.05)$, with no differences between the other parameters studied. Low tannin sorghum can be used in rabbit growth diets at substitution levels of $50 \%$ or $100 \%$ of maize participation without impairing zootechnical performance and digestibility.
\end{abstract}

Keywords: Zea mays, Sorghum bicolor, rabbits, nutrition

\section{INTRODUÇÃO}

O milho é o cereal mais importante na alimentação animal, sendo a principal fonte de energia nas dietas, em virtude de sua disponibilidade comercial e qualidade nutricional. No entanto, no período da entressafra em algumas regiões brasileiras, a produção é insuficiente para

Recebido em 22 de fevereiro de 2019

Aceito em 23 de outubro de 2019

E-mail: joaquimparreira@iftm.edu.br 
atender às demandas humana e animal (Fernandes et al., 2014), o que contribui para a elevação dos preços, afetando a cadeia produtiva animal.

Para minimizar essa situação, o sorgo vem sendo utilizado como um alimento alternativo na alimentação animal, principalmente nas regiões onde esse grão tem maior disponibilidade (Marques et al., 2007; Fialho et al., 2002). Do ponto de vista nutricional, quando comparado ao milho, o sorgo apresenta menor quantidade de óleo, energia e alguns aminoácidos (Fernandes et al., 2014), tem mais de $65 \%$ de amido, cerca de $80 \%$ de extrativos não nitrogenados, $2,5 \%$ de fibra bruta e entre $8,0 \%$ e $10 \%$ de proteína bruta, o que o torna rico em nutrientes digestíveis totais (Rostagno et al., 2017). Com esse valor nutricional e preço acessível, o sorgo tem substituído total ou parcialmente o milho utilizado na alimentação animal. Nas rações de frango de corte, é possível substituir o milho sem prejudicar o rendimento de cortes comerciais e as características químicas da carcaça (Carolino et al., 2014). O mesmo fato tem ocorrido com as codornas de corte (Moraes et al., 2016), na dieta de matrizes suínas híbridas (Moreira et al., 2013) e de suínos de engorda (Marques et al., 2007), bem como em dietas para peixes pacus juvenis (Sanches et al., 2016).

A substituição do milho pelo sorgo com alto teor de tanino na ração de coelhos mestiços Chinchila $X$ Nova Zelândia Branco, na fase de recria, não afetou ganho de peso, consumo de ração e conversão alimentar (Colnago et al., 1978; Falco et al., 1978). Quando compararam a substituição do milho pelo sorgo com baixo e alto teor de tanino na ração, Al-Mamary et al. (2001) observaram melhor desempenho dos animais que receberam milho e sorgo com baixo teor de tanino.

Os resultados encontrados na literatura, especificamente sobre o uso do sorgo na alimentação de coelhos, são escassos e antigos (Furlan et al., 2006; Al-Mamary et al., 2001; Muriu et al., 2002; Abubakar et al., 2006), por isso necessitam de avaliação mais cautelosa. Neste estudo, objetivou-se avaliar a inclusão do sorgo grão moído, sem tanino, na ração de coelhos em crescimento, comparando-se os efeitos sobre desempenho zootécnico e na digestibilidade.

\section{MATERIAL E MÉTODOS}

O estudo foi conduzido no setor de Cunicultura do Instituto Federal de Educação, Ciência e Tecnologia do Triângulo Mineiro (IFTM) Campus Uberaba, que fica localizado no município de Uberaba, entre as coordenadas geográficas de latitude de $19^{\circ} 45^{\prime} 27^{\prime}$ 'S e longitude de $47^{\circ} 55^{\prime} 36^{\prime \prime} \mathrm{W}$, na altitude de $764 \mathrm{~m}$, no período de 16 de agosto a 13 de setembro de 2018. Foram conduzidos dois ensaios, sendo um de desempenho zootécnico e outro de digestibilidade, aprovados pela Comissão de Ética no Uso de Animais do Instituto Federal de Educação, Ciência e Tecnologia do Triângulo Mineiro, com protocolo de aprovação número: Ceua-IFTM 02/2017.

O clima da região é caracterizado como Aw tropical quente, inverno seco e verão úmido, segundo classificação atualizada de Köppen (Beck et al., 2018). As estações são climaticamente definidas, apresentando estação fria e estação quente com características bem marcadas.

Os coelhos foram alojados em galpão de alvenaria, coberto com telhas de amianto e laterais teladas equipadas com cortina de plástico, gaiolas de arame galvanizado medindo $80 \times 60 \times 40 \mathrm{~cm}$, providas de bebedouros automáticos tipo chupeta e comedouros semiautomáticos de chapa galvanizada. Na parte inferior de cada gaiola, foi instalada uma bandeja telada para a separação de fezes e urina.

O delineamento experimental utilizado foi de blocos ao acaso (DBC), com três tratamentos: 1 $(\mathrm{TM})=$ ração base milho; 2 (TS) = ração base sorgo e $3(\mathrm{TMS})=50 \%$ de milho e $50 \%$ de sorgo, e 10 repetições, cada uma contendo dois coelhos da raça Nova Zelândia Branco, que foram desmamados aos 35 dias de idade, sendo alojados dois animais por gaiola, totalizando 20 animais por tratamento.

No ensaio de desempenho zootécnico, utilizaramse 60 coelhos machos da raça Nova Zelândia Branco, desmamados aos 35 dias de idade, sendo alojados dois animais por gaiola, os quais receberam uma ração e água ad libitum até que completassem 52 dias de idade e peso vivo médio de $1,520 \mathrm{~kg}$, quando começaram a receber as rações propostas nos tratamentos, até 
completarem 80 dias de idade, ou seja, receberam a ração proposta por 28 dias.

As rações utilizadas nos tratamentos foram formuladas de acordo com as recomendações de De Blas e Mateos (2010), peletizadas e compostas de milho moído, sorgo sem tanino moído, farelo de soja, feno de capim coast-cross, farelo de trigo, núcleo comercial para coelhos, fosfato bicálcico e sal comum (Tab.1).

As variáveis de desempenho zootécnico avaliaram o ganho médio de peso dos animais (GMP), o consumo de ração (CR) e a conversão alimentar (CA). Todos os animais foram pesados no início do experimento e a cada sete dias, durante quatro semanas, para determinação do peso médio por gaiola. Mediante o emprego do mesmo critério, a ração fornecida e as sobras foram pesadas para o cálculo do consumo de ração, obtendo-se a conversão alimentar pela razão entre o CR e o GMP.

Para a determinação da digestibilidade aparente de nutrientes das rações, seguiram-se as recomendações propostas por Perez et al. (1995), por meio de coleta completa de excretas durante quatro dias. Essa avaliação teve início quando os coelhos atingiram 60 dias de idade, de forma a garantir uma adaptação dos animais a cada dieta, por um período mínimo de sete dias. As fezes de cada gaiola foram coletadas na sua totalidade, uma vez ao dia, sempre às nove horas da manhã, acondicionadas em sacos plásticos fechados a vácuo e armazenadas em freezer, em temperatura de $-10^{\circ} \mathrm{C}$. Posteriormente, formaram-se amostras compostas das fezes de cada unidade experimental, que foram pesadas e acondicionadas em sacos de papel e levadas a uma estufa de ventilação forçada a $65^{\circ} \mathrm{C}$, durante 72 horas, para secagem e nova pesagem.

Tabela 1. Composição das rações experimentais com base na matéria original (\%)

\begin{tabular}{|c|c|c|c|}
\hline \multirow[t]{3}{*}{ Ingredientes utilizados } & \multicolumn{3}{|c|}{ Tipo de ração } \\
\hline & Milho (M) & Sorgo $(\mathrm{S})$ & $M(50 \%)+S(50 \%)$ \\
\hline & \multicolumn{3}{|c|}{$\%$} \\
\hline Milho & 52,23 & & 23,59 \\
\hline Sorgo & - & 43,74 & 23,50 \\
\hline Soja farelo & 22,94 & 20,04 & 20,55 \\
\hline Trigo farelo & - & 10,00 & 7,62 \\
\hline Feno capim coast-cross & 18,99 & 19,00 & 19,00 \\
\hline Fosfato bicálcico & 0,77 & 0,614 & 0,67 \\
\hline Núcleo para coelhos ${ }^{2}$ & 5,00 & 5,00 & 5,00 \\
\hline Sal comum & 0,08 & 0,08 & 0,08 \\
\hline Caulim & , & 1,53 & 50 \\
\hline \multirow[t]{2}{*}{ Total } & 100,00 & 100,00 & 100,00 \\
\hline & \multicolumn{3}{|c|}{ Composição Calculada $^{1}$} \\
\hline Energia digestível Mcal/kg & $2.500,00$ & $2.500,00$ & $2.500,00$ \\
\hline Proteína bruta & 16,00 & 16,00 & 16,00 \\
\hline Gordura & 2,47 & 2,11 & 2,33 \\
\hline Fibra bruta & 8,00 & 8,69 & 8,50 \\
\hline Cálcio & 1,28 & 1,27 & 1,28 \\
\hline Fósforo disponível & 0,40 & 0,40 & 0,40 \\
\hline Sódio & 0,30 & 0,30 & 0,30 \\
\hline Lisina total & 0,77 & 0,75 & 0,77 \\
\hline Metionina total & 0,37 & 0,35 & 0,36 \\
\hline
\end{tabular}

${ }^{1}$ Com base nos valores de composição química das matérias-primas.

${ }^{2}$ Níveis de garantia por kg do produto: cálcio (mín.) 160,00g/kg; cálcio (máx.) 220,00g/kg; fósforo (mín.) 35,00g/kg; sódio (mín.) 48,00g/kg; cobre (mín.) 165,00mg/kg; zinco (mín.) 715,00mg/kg; manganês (mín.) 440,00mg/kg; iodo (mín.) 14,30mg/kg; selênio (mín.) 2,20mg/kg; cobalto (mín.) 11,00mg/kg; vitamina A (mín.) 250.000,00UI/kg; vitamina D3 (mín.) 30.000,00UI/kg; vitamina E (mín.) 500,00UI/kg; vitamina K3 (mín.) 25,00mg/kg; ácido fólico (mín.) 50,00mg/kg; colina (mín.) 10,00g/kg; niacina (mín.) 375,00mg/kg; ácido pantotênico (mín.) 143,00mg/kg; vitamina B1 (mín.) 37,50mg/kg; vitamina B2 (mín.) 62,50mg/kg; vitamina B6 (mín.) 37,50mg/kg; vitamina B12 (mín.) $250,00 \mathrm{mcg} / \mathrm{kg}$; metionina (mín.) $23,80 \mathrm{~g} / \mathrm{kg}$; robenidina $1.003,00 \mathrm{mg} / \mathrm{kg}$. 
Após homogeneizadas, as amostras de fezes foram moídas em moinho tipo Wylle, com peneira de $1 \mathrm{~mm}$, para análise de matéria seca total (MS), proteína bruta $(\mathrm{PB})$, energia bruta (EB), fibra em detergente neutro (FDN) e fibra em detergente ácido (FDA) e extrato etéreo (EE), de acordo com Silva e Queiroz (2002).

Das amostras de ração e das fezes, determinou-se a composição química e o valor de energia bruta em calorímetro, seguido do cálculo de energia digestível, segundo metodologia de Silva e Queiroz (2002). Com base nos resultados, realizou-se o cálculo para o coeficiente de digestibilidade da matéria seca (CDMS), proteína bruta (CDPB), energia bruta (CDEB), fibra em detergente ácido (CDFDA), fibra em detergente neutro (CDFDN) e extrato etéreo (CDEE), conforme as recomendações de Perez et al. (1995), de acordo com a equação 1 :

Digestibilidade $(\%)=\frac{N I(g)-N E(g)}{N I(g)} \times 100$,

em que:

$\mathrm{NI}=$ nutriente ingerido;

$\mathrm{NE}=$ nutriente excretado.

Os dados obtidos foram submetidos à análise de variância (ANOVA), e as médias foram comparadas pelo teste de Tukey, em nível de 5\%, utilizando-se o programa estatístico Sisvar (Ferreira, 2014).

\section{RESULTADOS E DISCUSSÃO}

Ao se analisarem os resultados obtidos na substituição do milho por sorgo moído nas rações em níveis de $50 \%$ ou $100 \%$, foi observado que não houve comprometimento no consumo médio de ração (CRM), no ganho de peso médio (GPM) e na conversão alimentar (CA) dos animais (Tab. 2). Esses resultados confirmam que o sorgo utilizado como fonte de alimentação animal não é apenas uma alternativa de substituição do milho, mas é um produto que pode ser usado como a principal fonte de energia nas rações de coelhos, por possuir qualidade nutricional capaz de suprir a necessidade alimentar do animal.

Como as rações-teste foram formuladas com base isoenergética e isonutritiva, era esperado que houvesse uma ingestão de ração em quantidades iguais para satisfazer as exigências energéticas daqueles animais em teste, o que aconteceu neste estudo, ratificando a semelhança nutricional do milho e do sorgo para o uso na formulação de rações para coelhos.

Tabela 2. Consumo de ração médio (CRM), conversão alimentar (CA), ganho de peso médio (GPM), peso vivo médio inicial (PVMI) e final (PVMF) de coelhos em crescimento alimentados com rações contendo diferentes níveis de milho e sorgo

\begin{tabular}{|c|c|c|c|c|c|}
\hline \multirow[t]{3}{*}{ Variável } & \multicolumn{5}{|c|}{ Tipo de ração } \\
\hline & Milho (M) & Sorgo $(\mathrm{S})$ & $M+S$ & $\mathrm{P}$ valor & $\mathrm{CV}$ \\
\hline & \multicolumn{3}{|c|}{ 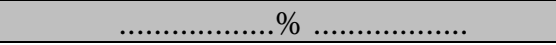 } & - & $\%$ \\
\hline CRM & 3,48 & 3,33 & 3,57 & 0,52 & 13,5 \\
\hline $\mathrm{CA}$ & 3,71 & 3,31 & 3,70 & 0,32 & 18,2 \\
\hline GPM & 0,96 & 1,01 & 0,98 & 0,72 & 13,6 \\
\hline PVMI (kg) & 1,52 & 1,51 & 1,52 & -- & -- \\
\hline PVMF (kg) & 2,48 & 2,52 & 2,50 & -- & -- \\
\hline
\end{tabular}

Médias seguidas de mesmas letras, na mesma linha, não diferem entre si pelo teste de Tukey $(\mathrm{P}>0,05)$.

Em estudo semelhante, Colnago et al. (1978) e Falco et al. (1978) avaliaram a substituição do milho em $50 \%$ e $100 \%$ pelo sorgo com alto teor de tanino em ração para alimentação de coelhos mestiços Chinchila x Nova Zelândia Branco na fase de recria, concluindo que essa substituição não afetou o CRM, a CA e o GPM dos animais utilizados. No entanto, os valores observados pelos autores supracitados, para essas variáveis, são visivelmente inferiores aos observados no presente estudo, o que pode estar relacionado ao fornecimento da ração na forma farelada e ao uso de machos e fêmeas, sem levar em consideração o sexo, bem como à presença de tanino (3\%) no sorgo utilizado. Estudos realizados por AlMamary et al. (2001), ao compararem rações $60 \%$ de milho, com duas rações de sorgo grãos, uma com baixo tanino (até $0,5 \%$ ) e outra com alto tanino (superior a 1,0\%), indicaram que a ração até $0,5 \%$ de tanino não comprometeu o GPM, o CRM e a CA - resultados esses semelhantes aos obtidos neste estudo, diferentemente daquela que 
tinha até $1,0 \%$ de tanino, que comprometeu os mesmos índices avaliados. Resultados semelhantes foram obtidos por Furlan et al. (2006), que utilizaram ração composta por grão úmido de sorgo (baixo tanino), com total substituição do milho, na alimentação de coelhos em crescimento, sem comprometer o desempenho.

O sorgo com baixo tanino vem sendo usado em substituições parciais ou totais do milho para alimentação de diferentes espécies animais, que têm apresentado elevadas taxas de desempenho nutricional, algumas vezes até superiores aos animais alimentados com rações de milho, por exemplo: em codornas (Moraes et al., 2016), frango de corte (Pimentel et al., 2007; Campos et al., 2017; Garcia et al., 2005) e suínos (Fialho et al., 2002; Moreira et al., 2013; Marques et al., 2007).

Os coeficientes de digestibilidade aparente da matéria seca (CDMS), da energia bruta (CDEB), do extrato etéreo (CDEE) e da fibra em detergente ácido (CDFDA) não foram influenciados com a substituição do milho pelo sorgo, nos níveis de $50 \%$ ou $100 \%$, na dieta dos coelhos. No entanto, a total retirada do milho da ração $(100 \%$ pelo sorgo) proporcionou a redução nos coeficientes de digestibilidade aparente da proteína bruta (CDPB) e da fibra em detergente neutro (CDFDN) (Tab. 3).

Tabela 3. Coeficientes de digestibilidade aparente da matéria seca (CDMS), proteína bruta (CDPB), energia bruta (CDEB), extrato etéreo (CDEE), fibra em detergente ácido (CDFDA), fibra em detergente neutro (CDFDN) de coelhos em crescimento alimentados com rações contendo diferentes níveis de milho e sorgo

\begin{tabular}{llllll}
\hline \multirow{2}{*}{ Variável } & \multicolumn{5}{c}{ Tratamentos } \\
\cline { 2 - 5 } & TM & TS & TMS & P valor & CV \\
\cline { 2 - 5 } & \multicolumn{5}{c}{$\%$} \\
\hline CDMS & 80,47 & 78,71 & 78,37 & 0,0954 & 2,23 \\
CDPB & $85,90 \mathrm{a}$ & $81,83 \mathrm{~b}$ & $82,44 \mathrm{~b}$ & 0,0178 & 2,90 \\
CDEB & 75,52 & 73,54 & 75,40 & 0,4628 & 4.33 \\
CDEE & 80,95 & 78,36 & 83,04 & 0,4443 & 8,23 \\
CDFDN & $74,75 \mathrm{a}$ & $70,70 \mathrm{~b}$ & $70,60 \mathrm{~b}$ & 0,0153 & 3,54 \\
CDFDA & 54,13 & 54,58 & 51,36 & 0,2978 & 7,46 \\
\hline
\end{tabular}

Médias seguidas de mesmas letras, na mesma linha, não diferem entre si pelo teste de Tukey (P>0,05).

Essa redução no CDPB pode estar associada à presença da cafirina na ração, pois o sorgo tem uma composição média de $54,7 \%$ de cafirina, $30,8 \%$ de glutelina, $7,5 \%$ de albumina e $7,0 \%$ de globulina (Virupaksha e Sastry, 1968; Ali et al., 2009), considerando que a concentração e composição da cafirina é um fator determinante da digestibilidade dos aminoácidos essenciais no grão. Além disso, a ração à base de sorgo é rica em aminoácido sulfurado (cisteína), que é resistente à penetração de água e enzimas, por isso retarda a degradação física e enzimática do amido e da proteína (Fernandes et al., 2014; Fialho et al., 2002; Marques et al., 2007).

No tratamento com $100 \%$ de ração à base de sorgo, observou-se um menor CDFDN. Segundo Schofield et al. (2001) e Makkar (2003), a presença do tanino no sorgo pode ser considerada um fator antinutricional, pois reduz a taxa de digestibilidade de proteínas e fibra. Entretanto, o sorgo utilizado no presente estudo não possui tanino, logo tal hipótese deve ser descartada, conforme comprovado pelo melhor desempenho de ganho de peso e conversão alcançados nas três formulações avaliadas neste estudo (milho $(100 \%)$, sorgo $(100 \%)$, milho $(50 \%)+$ sorgo $(50))$.

De forma geral, o sorgo possui um teor de fibra bruta em torno de $2,89 \%$ enquanto o milho é de cerca de 1,73\% (Rostagno et al., 2017), o qual influenciou o nível de fibra bruta das rações neste estudo (Tab. 1).

Normalmente, digestibilidade de fibra é muito baixa em coelhos, devido principalmente, ao tempo de passagem e à taxa de retenção dos alimentos no trato gastrointestinal (Herrera et al., 2001). Ressalta-se, portanto, que o tempo médio de retenção cecal é relativamente curto nos coelhos e os valores de CDFDN são geralmente mais baixos quando tomadas como referências outras espécies de herbívoros e/ou suínos (De 
Blas, 2013). Isso corrobora os resultados encontrados para o coeficiente digestibilidade da fibra em detergente neutro (CDFDN) neste estudo.

É importante registrar que todos os animais chegaram ao final do experimento, após terem recebido as rações propostas por um período de 28 dias, com excelente saúde e sem taxa de mortalidade.

\section{CONCLUSÃO}

O estudo em tela indicou que o consumo de ração médio (CRM), a conversão alimentar (CA) e o ganho de peso médio (GPM) de coelhos em crescimento não foram alterados pela substituição do milho pelo sorgo, nos níveis de $50 \%$ e $100 \%$. Os resultados de digestibilidade demonstraram maiores CDPB e CDFDN na ração base milho $(\mathrm{P}<0,05)$, não havendo diferenças entre os demais parâmetros estudados. Conclui-se que sorgo com baixo teor de tanino pode ser usado nas rações de crescimento de coelhos em níveis de substituição de $50 \%$ ou $100 \%$ da participação do milho, sem prejuízos para o desempenho zootécnico e a digestibilidade.

\section{AGRADECIMENTOS}

Os autores agradecem ao Instituto Federal do Triângulo Mineiro, Campus Uberaba, pela infraestrutura disponibilizada, e à Coordenação de Aperfeiçoamento de Pessoal de Nível superior (Capes), pelo financiamento do projeto.

\section{REFERÊNCIAS}

ABUBAKAR, M.; DOMA, U.D.; KALLA, D.J.U. et al. Effects of dietary replacement of maize with malted or unmalted sorghum on the performance of weaner rabbits. Livest. Res. Rural Dev., v.18, n.5, 2006. Disponível em: <http://www.lrrd.org/lrrd18/5/abub18065.htm>. Acesso em: 27 dez. 2018.

ALI, N.M.M.; EL TINAY, A.H.; ELKHALIFA, A.E. O. et al. Effect of alkaline pretreatment and cooking on protein fractions of a high-tannin sorghum cultivar. Food chem., v.114, p.646-648, 2009.
AL-MAMARY, M.; MOLHAM, A.H.; ABDULWALI, A.A.; AL-OBEIDI, A. In vivo effects of dietary sorghum tannins on rabbit digestive enzymes and mineral absorption. Nutr. Res., v.21, p.1393-1401, 2001.

BECK, H.E.; ZIMMERMANN, N.E.; MCVICAR, T.R. et al. Present and future Köppen-Geiger climate classification maps at 1km resolution. Sci. Data, v.5, p.1-12, 2018.

CAMPOS, C.F.A.; SIQUEIRA, J.C.; RODRIGUES, K.F. et al. Nutritional evaluation of sorghums grown with different organic fertilizers for slow-growing broilers. Semin. Ciênc. Agrár., v.38, p.3341-3352, 2017.

CAROLINO, A.C.X.G.; SILVA, M.C.A.; LITZ, F.H. et al. Rendimento e composição de carcaça de frangos de corte alimentados com dietas contendo sorgo grão inteiro. Biosci. J., v.30, p.1139-1148, 2014.

COLNAGO, G.L.; MELLO, H.V.; CAMPOS, O.F. Substituição do milho pelo sorgo na ração de recria de coelhos. Seiva, v.38, p.1-6, 1978.

DE BLAS, J.C. Nutritional impact on health and performance in intensively reared rabbits. Animal, v.7, Suppl.1, p.102-111, 2013.

DE BLAS, J.C.; MATEOS G.G. Feed Formulation. In: DE BLAS, J.C.; WISEMAN, J. The nutrition of the rabbit. 2.ed. Cambridge: $\mathrm{CAB}$ International, 2010. p.222-232.

FALCO, J.E.; MELLO, H.V.; CAMPOS, O.F. Substituição do milho pelo sorgo na ração de coelhos na fase de engorda. Seiva, v.38, p.11-17, 1978.

FERNANDES, E.A.; CARVALHO, C.M.C.; LITZ, F.H. et al. Viabilidade técnica e econômica da utilização de grãos de sorgo para monogástricos. Inf. Agropecu., v.35, p.73-81, 2014.

FERREIRA, D.F. Sisvar: a guide for its bootstrap procedures in multiple comparisons. Ciênc. Agrotec., v.38, p.109-112, 2014.

FIALHO, E.T.; AUGUSTO, J.; LIMA, F.D.E. et al. Substituição do milho pelo sorgo sem tanino em rações de leitões: digestibilidade dos nutrientes e desempenho animal. Rev. Bras. Milho Sorgo, v.1, p.105-111, 2002. 
FURLAN, A.C.; SCAPINELLO, C.; MOREIRA, I.; MARTINS, E.N. Avaliação nutricional da silagem de grãos úmidos de sorgo de baixo ou de alto conteúdo de tanino para coelhos em crescimento. Rev. Bras. Zootec., v.35, p.775-784, 2006.

GARCIA, R.G.; MENDES, A.A.; COSTA, C. et $a l$. Desempenho e qualidade da carne de frangos de corte alimentados com diferentes níveis de sorgo em substituição ao milho. Arq. Bras. Med. Vet. Zootec., v.57, p.634-643, 2005.

HERRERA， A.D.P.N; SANTIAGO, G.S.; MEDEIROS, S.L.S. Importância da fibra na nutrição de coelhos. Ciênc. Rural, v.31, p.557$561,2001$.

MAKKAR, H.P.S. Effects and fate of tannins in ruminant animals, adaptation to tannins, and strategies to overcome detrimental effects of feeding tannin-rich feeds. Small Ruminant Res., v.49, p.241-256, 2003.

MARQUES, B.M.F.P.P.; ROSA, G.B.; HAUSCHILD, L. et al. Substituição de milho por sorgo baixo tanino em dietas para suínos: digestibilidade e metabolismo. Arq. Bras. Med. Vet. Zootec., v. 59, p.767-772, 2007.

MORAES, C.A.; FERNANDES, E.A.; SILVEIRA, M.M. et al. Performance and meat chemical composition of quails fed with different sorghum levels instead of corn. Ciênc. Rural, v.46, p.933-936, 2016.

MOREIRA, F.R.C.; COSTA, A.N.; MARTINS, T.D.D. et al. Substituição parcial do milho por sorgo granífero na alimentação de matrizes suínas primíparas nos períodos de puberdade e gestação. Arq. Bras. Med. Vet. Zootec., v.65, p.902-908, 2013.
MURIU, J.J.I.; NJOKA-NJIRU, E.N.; TUITOEK, J.K; NANUA, J.N. Evaluation of sorghum (Sorghum bicolor) as replacent for maize in the diet of growing rabbits (Oryctolagus cuniculus. Asian-Aust. J. Anim. Sci., v.15, p.565$569,2002$.

PEREZ, J.M.; LEBAS, F.; GIDENNE, T. et al. European reference method for in vivo determination of diet digestibility in rabbits. World Rabbit Sci., v.3, p.41-43, 1995.

PIMENTEL, A.C.S.; DUTRA JÚNIOR, W.M.; LUDKE, M.C.M.M. et al. Substituição parcial do milho e farelo de soja por sorgo e farelo de caroço de algodão extrusado em rações de frangos de corte. Acta Sci. Anim. Sci., v.29, p.135-141, 2007.

ROSTAGNO, H.S.; ALBINO, L.F.T.; DONZELE, J.L. et al. Tabelas brasileiras para aves e suínos: composição de alimentos $\mathrm{e}$ exigências nutricionais. 3.ed. Viçosa: UFV, 2017. 252p.

SANCHEZ, M.S.S.; NASCIMENTO, M.S.; HISANO, H. substituição do milho pelo sorgo em dietas para juvenis de pacu. Pesqui. Agropecu. Bras., v.51, p.1-8, 2016.

SCHOFIELD, P.; MBUGUA, D.M.; PELL, A.N. Analysis of condensed tannins: a review. Anim. Feed Sci. Technol., v.91, p.21-40, 2001.

SILVA, D.J.; QUEIROZ, A.C. Análise de alimentos: métodos químicos e biológicos. 3.ed. Viçosa: UFV, 2002. 235p.

VIRUPAKSHA, T.K.; SASTRY, L.V.S. Studies on the protein content and amino acid composition of some varieties of grain sorghum. J. Agric. Food Chem., v.16, p.199-203, 1968. 